\title{
THE INTERNAL UNIVERSITY FACTORS IN DETERMINING THE GRADUATES' PERFORMANCE IN THE LABOUR MARKET: EVIDENCE FROM SYRIAN UNIVERSITIES
}

\author{
Alaa SALHANI ${ }^{1 *}$, Victoria KHNOUF ${ }^{2}$, Rania AL-ZRAIR ${ }^{3}$, Serene DALATI ${ }^{4}$ \\ ${ }^{1,3}$ Finance and Accounting Department, Faculty of Business, Arab International University, Damascus, Syria \\ ${ }^{2,}{ }^{4}$ Management and Marketing Department, Faculty of Business, Arab International University, Damascus, Syria
}

*E-mail: a-salhani@aiu.edu

\begin{abstract}
Purpose - this study aims to investigate internal university factors that affect graduates' performance in the Syrian labour market.

Research methodology - the applied methodology employes two questionnaire surveys distributed to a sample of graduates and sample of Work Organizations (WO) for the period from 2012 to 2017. The research uses descriptive and analytical methodologies by applying binary logistic regression, linear regression, T-test and measuring some descriptive statistical indicators.

Findings - the research findings indicate that WO collaboration is the main determinant of performance that is measured by two variables, the first one is being selected in a relevant job, and the second one is a performance at work. Moreover, GPA, attendance, and study's language are determinants in different levels but less than WO collaboration to the graduates' performance.
\end{abstract}

Research limitations - further research could expand the sample and consider other factors like teaching staff and quality standards in order to get more comprehensive results.

Practical implications - universities and business sector can benefit from this research by enhancing WO collaboration as well as curriculums that need to be updated and suited with the need of business. Universities should also consider English as the core language of courses.

Originality/Value - this is the first research in Syria that investigate the internal university factors, taking into consideration two different views of points, the graduates and business sector as well as using many different statistical methods.

Keywords: collaboration, labour market, performance, university.

JEL Classification: I29.

Conference topic: Contemporary Organizations Development Management.

\section{Introduction}

University students are asking for their rights as customers in the labour marketplace which requires advanced credentials, seeing a shift from "inquisitive" to "acquisitive" learners (Eagle \& Brennan, 2007; Guilbault, 2016; Clayson \& Haley, 2015; Lauder, Brown, Dillabough, \& Halsey, 2006). The responsible for employment believe that Graduates of higher education lack much practical experience, which is required by the work environment (Junek, Lockstone \& Mair, 2009). There are many cases in which graduates have encountered difficulties in employment because they do not have the required skills such as communication skills (Alias, Sidhu, \& Fook, 2013). The Syrian labour Market is under constant Pressure because of the influx of young people with an increase of working age population, taking into consideration that there is no matching between the Universities research and the Labour market requirement (Salhani \& Khnouf, 2017). Considering that, some private universities are participating in good preparation, due to their new curricula, which has the aim to prepare them to afford the requirement of the Syrian labour market. The Syrian government plays a major role in the supervision and control of the higher education system. The system is highly centralized; the Government plays a regulatory role for public and private universities. One of the most important role of universities is qualifying the graduates to enter the labour market and achieving good performance as well. Achieving that role will lead to major benefits to the university, country, and business sector. 
Universities that qualify the graduates will be classified as one of the most prestigious universities and will have a high ranking and reputation. Countries will enjoy a low unemployment rate and high economic growth. Business sector will enjoy increasing its productivity as well as increasing in its return on investment. This research is questioning if there are internal university factors that determine the graduates' performance in the labour market. By identifying these factors, universities can focus on them in order to enhance their outputs. The following sections are as follow: the second section discusses the literature reviews about similar topics. Section 3 presents the research problem and the main questions that need to be answered. Section 4 explains how data is selected as well as methodology and statistical tools that are implemented. Findings are discussed in section 5 . Conclusion is presented in section 6 with summarizing results, recommendations for universities and students. Section 7 presents study limitations.

\section{Literature review}

Researchers have explored many factors that universities should consider in order to qualify their graduates as well as to collabourate with the business sector. The following some these research articles and how this research differentiate from them and its main value added.

Taran and Liv (2015) investigated industry collaboration between higher education institutions and business sectors. This research aimed to show an experimentally based investigation of how collaboration between higher education institutions and business sector can enhance graduate skills, experiences and ability to be selected in a good job. Research found that $77 \%$ of the students have made different kinds of collaboration with the business sector during their stage of the study. They have noticed also that there is a difference between the level and the kind of collaboration. Nevertheless, the advantages of participating differ by kind of collaboration. Project-based collaboration is significantly and positively correlated with completing the study period on time. Moreover, graduates who have collabourated in either performing a project with business sector or internship period have more facilities to response effectively to labour market requirements than their peers do. The research has shown also when controlling of subject field differences and students' abilities. However, this research did not consider the business sector perspective regarding the determinants of graduates' performance in the labour market.

Ward, McAdie, Bravington, and King (2012) also investigated associations between work experience and acquired skills. The purpose of the paper is to link work experience to the development of acquired skills, by enhancing the reflection concerning the psychological concepts identified from this quantitative study. The researchers have explored the process of designing and analysing a qualitative study into multiple WIL (work integrated learning) experiences. They have explored their pilot work with personal construct psychology techniques and the modifications developed from their trials.

Pheko and Molefhe (2017) also conducted research on graduates' employability skills in Botswana. Researchers use many different approaches to investigate students' knowledge regarding the requirement of the business sector of skills and attributes in Botswana University. They have assessed if there are any differences in terms of skills and attributes that the students consider essential versus the ones that have been reported as important by the global labour market. They have proposed a framework for ensuring the concept of the development of employability skills and attributes by different actors in the labour market. The paper has suggested a framework examining working opportunities as a main responsibility shared by training organizations, business sector, incumbent employees, and the potential employees. However, this research did not differentiate between the two different stages the graduate follows the graduation, the first one of being selected in the relevant job and their performance at work. Jackson (2014) examined factors influencing job attainment in recent graduates in Australia in higher education institutions. The paper investigates the factors that influence the employability in order to find approaches for improving the outcomes in Australia. The research has distributed a survey for the graduates of a bachelor degree in two years 2011 and 2012. The research analysed data to determine the main factors that influence employability. However, this research did not consider the business view of point regarding the graduates' performance in the labour market.

Pool and Sewell (2007) examined graduate employability skills and investigated the practical model by explaining its elements, and why they have been included and explained the main value of that model. The study considers employability as a "lifelong cycle". According to this research, "There will always be aspects of a person's employability that would benefit from improvement". The proposed model does not characterize a process which enables the student to continue their studies in higher education and then graduates with "lifelong employability". However, the elements within the model should be reconsidered over time to make sure of its ability to fit changes in the business and higher education environment. Moreover, the proposed model did differentiate between the two consecutive stages that follow the graduation, which has a particular interest nowadays.

Bratti, McKnight, Naylor, and Smith (2004) examined official performance indicators according to the population of students in the United Kingdom higher education. They explained how this produced potentially onesided performance measures, as this population of students might not represent the whole population of leavers 
from each organization. Meanwhile, those who leave the university, do not get enough qualifications and do not respond to the FDS are not considered within the official analysis. The research compares employment-related measures upon those students who responded to the FDS with different methods, which handle the possible nonrandom nature of this group of students who leave the university.

Sumanasiri, Yajid, and Khatibi (2015) examined graduate employability and considered the main objectives of university education. The researchers have discussed the role of governments, funding organizations, students and parents on universities around the world. They have explored accreditation bodies, as it appears to measure the quality of education through the contributions made towards employability. They would assume that employability of university graduates to be significant, and an incentive motive for the researched area. However, the real situation appears to be one which requires the urgent attention of all stakeholders of university education. A review of the literature on graduate employability is considered to be at most need today so that the actual research paper achieves this by summarizing the major articles on university graduate employability by theoretical frameworks and empirical studies. Despite a large number of studies, graduate employability suffers from of lack of theoretical control and politicization, which have become major obstacles for future developments of this concept.

Hongjie and Zhenjia (2019) peered on high-level talent advancement in universities and the improvement of the demand for talents by employers; researches on college students' employability have been valued by scholars and universities. In addition, they have indicated the role of implementing excellent employability which has been a shared concern for both college students and universities. As well, the authors have presented the concept of employability that has evolved over time. Moreover, extrinsic and intrinsic Scholars will enrich the meaningful of college students' employability cause of the variety perspectives.

Tenorio-Rodríguez, Padilla-Carmona, and González-Monteagudo (2018) examined a European research project, in which six universities sharing the same target; improving the employability of non-traditional university students and graduates (youths and adults) in order to ensure a soothing transition process into the labour market. Research, until now, is working to complete the image and perception about the ways of accessing the job market. The research indicates that experiences of non-traditional students who move from university to the labour market have been mostly ignored. This is why it is critical to gather opinions, experiences and perceptions of non-traditional students which taking into account their views and subjective perspectives. The process and results are presented of a qualitative analysis developed from biographical interviews with non-traditional students.

Karoly (2010) examines the trends regarding the main role of education in the labour market and considers the implications for education in the selected countries namely Bahrain, Kuwait, Oman, Qatar, Saudi Arabia, and the United Arab Emirates. The study examines gender differences, where applicable, in each of these countries in order to more accurate results. The paper investigates trends of educational attainment overall in these gulf countries, evidence of the quality of the education systems and the graduates they produce, and the labour market advantages of higher educational attainment. The paper finds many different challenges encountering the selected countries in enhancing good education systems and well-functioning labour markets to meet the labour force needs in the public and private sectors.

This is the first research in Syria that investigate the internal university factors in determining the graduates' performance in the labour market. Taking into consideration two different view of points, the graduates and business sector by disseminating two different questionnaires. This research has used many different statistical methods in order to find internal factors like logistic regression, linear regression, $\mathrm{T}$ test, alpha Cronbach. It also considers two different stages the graduate follow (being selected in the relevant job and their performance at work) in examining the internal factors. This research aims to help universities and students to find the main factors that they should consider in order to enhance the graduate performance and efficiency in the labour market in two consecutive stages.

\section{Research problem}

There are two successive stages follow the graduation. Every graduate tries to achieve a good performance in each stage. In the first stage, graduates try to be selected in a relevant job. While in the second stage, they do their best in order to perform well at work by applying the knowledge, skills and competencies that they have acquired during their studies.

This research aims to answer the following questions in the two stages:

1. What are the main internal university factors in determining the graduates' performance of being selected in the relevant job in the labour market?

2. What are the main internal university factors in determining the graduates' performance after being selected in the labour market?

Answering these questions will enable us to find the main determinants that universities should focus on in order to achieve one of their important role of qualifying the graduate to enter the labour market and achieving good performance as well. 
The Figure 1 below explains the two successive stages that follow the graduation and the main question of each stage that need to be answered.

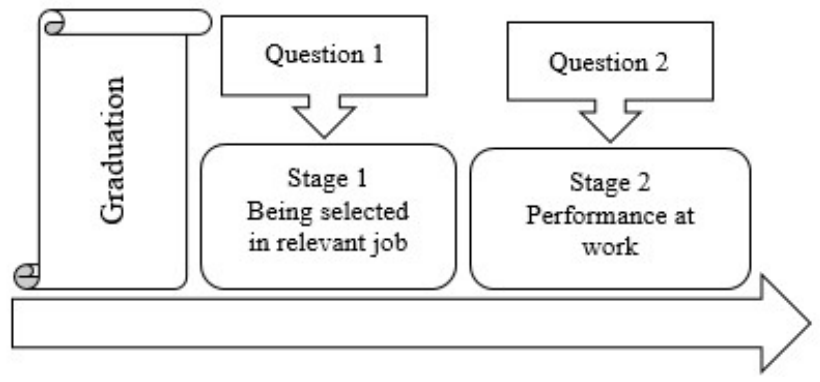

Figure 1. The two successive stages that follow the graduation (source: researchers)

\section{Sample and methodology}

The data was gathered by disseminating two surveys as follow:

- The first one was disseminated to 850 graduates from several Syrian universities, 365 responses were received from graduates in 10 different universities during 2012-2017. The following statistical approaches are used to analyze the questionnaire in order to answer the research problems: Binary Logistic regression, linear regression, Cronbach Alpha reliability test, Shapiro-wilk for normality test, mean and standard deviation.

- The graduates' performance is measured in the first stage by being selected in the relevant job or not (1, 0 ), and measured in the second stage by calculating the mean of answers to Likert-scale questions regarding the graduates' performance at work.

- The second one was disseminated to 125 different businesses, 68 complete responses from different Syrian businesses were received. The following statistical approaches are used to analyze the questionnaire in order to answer the research problems: Cronbach Alpha reliability test, mean and standard deviation, T-test. The graduates' performance is measured in the first and second stage by calculating the mean of answers of Liker-scale questions regarding the graduates' selection and performance at work. These internal university factors have been used as independent variables (Table 1 and Figure 2).

\begin{tabular}{|c|}
\hline Independent Variables \\
\hline WO collaboration \\
\hline GPA \\
\hline Attendance \\
\hline Language \\
\hline Type \\
\hline Working \\
\hline Completing \\
\hline Gender \\
\hline
\end{tabular}

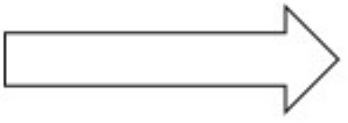

\begin{tabular}{|l|}
\hline \multicolumn{1}{|c|}{ Dependent variables } \\
\hline Stage one: Being selected in relevant job \\
\hline Stage two: Performance at work \\
\hline
\end{tabular}

Figure 2. Research model (source: researchers)

Table 1. Independent variables (source: researchers)

\begin{tabular}{|c|l|l|l|}
\hline & \multicolumn{1}{|c|}{ Variable } & \multicolumn{1}{|c|}{ Explanation } & \multicolumn{1}{c|}{ Measurement method } \\
\hline 1 & WO collaboration & $\begin{array}{l}\text { Work Organizations collaboration: } \\
\text { Internship or mutual research with business }\end{array}$ & Yes =1, No $=0$ \\
\hline 2 & GPA & Grade Point Average & $0-4$ \\
\hline 3 & Attendance & Attendance Ratio & $1-5$ \\
\hline 4 & Language & Language of study & English $=1$, Arabic $=0$ \\
\hline 5 & Type & Type of university & Private $=2$, Public $=1$ \\
\hline 6 & Working & Working during study & $\begin{array}{l}\text { No work }=1, \text { work not related to study }=2, \\
\text { work related to study }=3\end{array}$ \\
\hline 7 & Completing & Completing study on time & On time $=2$, more time $=1$ \\
\hline 8 & Gender & Female or Male & Female $=2$, Male $=1$ \\
\hline 9 & $\begin{array}{l}\text { Being selected in the } \\
\text { relevant job }\end{array}$ & $\begin{array}{l}\text { Being selected in the relevant job in the first } \\
\text { year after the graduation. }\end{array}$ & Yes $=1$, No $=0$ \\
\hline 10 & Performance at work & $\begin{array}{l}\text { Ability to add value to their job and apply } \\
\text { what they have acquired during their studies }\end{array}$ & $1-5$ \\
\hline
\end{tabular}




\section{Findings and discussion}

In this section, the research will answer the two questions that have been asked in the research problem and will discuss the results:

\subsection{First question: What are the main internal university factors in determining the graduates' performance of being selected in the relevant job in the labour market?}

By using logistic regression to analyze the graduates' data to specify the main internal university factors in determining the graduates' performance of being selected in the relevant job (see Table 2), the research found that two variables increase the probability of the graduate of being selected in a relevant job, and not being mal-adapted. The first variable is WO collaboration, which means mutual research that the students performed as well as the internship have a major role in qualifying the graduates to enter the labour market, due to the acquired information about the requirements of the labour market. The second variable is GPA, which means that achieving their curriculum in a relevant performance will increase their probability of being selected in a relevant job.

Table 2. Binary logistic regression of the probability of not being mal-adapted on the labour market one year after graduation based on the graduates' data (source: researchers)

\begin{tabular}{|c|c|c|c|}
\hline & \multicolumn{2}{|c|}{ Dependent variable: Being selected in the labour market } \\
\hline & B & SE & Sig \\
\hline WO collaboration & 0.840 & 0.429 & 0.050 \\
\hline GPA (0-4) & 1.796 & 0.445 & 0.000 \\
\hline Attendance & -0.054 & 0.125 & 0.663 \\
\hline Language & 0.041 & 0.420 & 0.921 \\
\hline Type & -0.695 & 0.444 & 0.117 \\
\hline Working & -0.015 & 0.175 & 0.930 \\
\hline Completing & 0.192 & 0.299 & 0.522 \\
\hline Gender & 0.368 & 0.289 & 0.001 \\
\hline Constant & -4.10 & 1.289 & \\
\hline Cox and Snell R square & 0.108 & & \\
\hline Nagelkerke R square & 0.164 & & \\
\hline No. of observations & 365 & & \\
\hline
\end{tabular}

On the other hand, by using $\mathrm{T}$ test to analyze the questionnaires that were disseminated to business sector, the research found that they only consider the WO collaboration as the main determinant of the graduates' selection in a relevant job, and they do not concern about the graduates' GPA, attendance, and English language (see Table 3). Consequently, the main factor in determining the graduates' performance by considering two different views of points in the first stage is WO collaboration. GPA still play an important role especially by analyzing the graduates' data but less than the WO collaboration.

Table 3. Using $\mathrm{T}$ test to examine the answers of the business sector regarding the graduates' selection in the relevant job (source: researchers)

\begin{tabular}{|c|c|c|c|}
\hline & Mean & SD & Sig \\
\hline WO collaboration & 3.88 & 0.89 & 0.000 \\
\hline GPA & 2.26 & 1.00 & 0.000 \\
\hline Attendance & 1.97 & 0.88 & 0.000 \\
\hline English & 2.9 & 0.94 & 0.374 \\
\hline
\end{tabular}




\subsection{Second question: What are the main internal university factors in determining the graduates' performance after being selected in the labour market?}

By using linear regression to analyze the graduates' data to specify the main internal university factors in determining the graduates' performance at work after being selected. The research found four variables positively affect the performance of the graduates at work (see Table 4).

Table 4. Linear regression for the impact of internal university factors on the graduates' performance at work based on the graduates' data (source: researchers)

\begin{tabular}{|c|c|c|c|}
\hline & \multicolumn{3}{|c|}{$\begin{array}{c}\text { Dependent variable: } \\
\text { Performance at work } \\
\text { Likert scale (1-5) } \\
\text { Cronbach's Alpha =0.934 }\end{array}$} \\
\hline WO collaboration & \multicolumn{2}{|c|}{ Sig } \\
\hline GPA (0-4) & B & 0.103 & 0.017 \\
\hline Attendance (1-5) & 0.246 & 0.129 & 0.000 \\
\hline Language & 0.860 & 0.039 & 0.000 \\
\hline Type of university & 0.142 & 0.130 & 0.000 \\
\hline Working & 1.094 & 0.122 & 0.446 \\
\hline Completing & -0.093 & 0.051 & 0.798 \\
\hline Gender & -0.013 & 0.101 & 0.624 \\
\hline Constant & 0.050 & 0.086 & 0.000 \\
\hline R square & 0.048 & 0.358 & \\
\hline Adjusted R square & -2.03 & & \\
\hline No. of observations & 0.59 & & \\
\hline
\end{tabular}

The first variable is WO collaboration, which means mutual research that the students performed as well as the internship play a major role in qualifying the graduates to perform better in the labour market. The second variable is GPA, which indicates that the higher the GPA is, the more the graduate has been interested in their study achievement, and have a higher ability to apply their knowledge in the labour market to achieve a better performance. The third variable is the attendance, which means, as much the students attend as much their performance in labour market would be better due to practical issues they have earned through attending which they would not be acquired through individual learning. The fourth variable is the English language, where the graduates who studied in English can perform better and apply their knowledge in the labour market more than those who studied in the Arabic language. This due to the fact that some private universities are adapting the advanced European curriculum, which integrates the necessary practical applications for the labour market more than universities, which have an old Arabic curriculum. On the other hand, by using $t$ test to analyze the questionnaires that were disseminated to business sector, the research found that they only consider the WO collaboration as the main determinant of the graduates performance at work, and they do not concern about the graduate GPA, attendance, and English (see Table 5). Consequently, the main factor in determining the graduates' performance by considering two different views of points in the second stage is WO collaboration. GPA, Attendance, and English still play an important role especially by analyzing the graduates' data but less than the WO collaboration.

Table 5. Using $\mathrm{T}$ test to examine the answers of the business sector regarding the graduates' performance at work (source: researchers)

\begin{tabular}{|c|c|c|c|}
\hline & Mean & SD & Sig \\
\hline WO collaboration & 3.38 & 1.35 & 0.022 \\
\hline GPA & 2.07 & 0.997 & 0.000 \\
\hline Attendance & 1.63 & 0.771 & 0.000 \\
\hline English & 2.5 & 1.113 & 0.000 \\
\hline
\end{tabular}




\section{Conclusions and recommendations}

Universities should play an important role in the graduates to enter the labour market and achieving a good performance. This paper is attempted to examine the main internal university factors that affect the graduates' performance in the labour market in two consecutive stages. The first stage of being selected in the relevant job and the second stage regarding their performance at work. Two different questionnaires were disseminated to both graduates and the business sector in Syria. In addition, different statistical approaches were used such as binary logistic regression, linear regression, and T-test. By analyzing the data of the graduates and business sector, the research finds that WO collaboration is the main determinant of both the graduates' selection in a relevant job and having a good performance at work. By analyzing the data of the graduates, the research finds GPA, English language, and attendance plays a significant role in determining the graduate's performance in the first stage of their selection. In addition, only GPA plays a significant role in determining the graduates' performance at work. Other variables like type of university, working during the study, completing a study on time, and gender do not have a significant impact on the graduates' performance neither in the first nor in the second stage. This paper recommends Syrian universities to enhance all types of collaborations with business sector such as mutual research and internships (Salhani \& Khnouf, 2017). In addition, updating their curriculums to be compatible with the need of Syrian work organizations. The Collaboration between the business sector and universities has proved to be the best way to enhance university responsiveness for continuous change in the requirement of the labour market. Both of them should cooperate to integrate theoretical knowledge with real world applications. The research also recommends Syrian students to perform mutual research and internships with Syrian business sector. Moreover, choosing the university that always updates its curriculum within the English language in some or all courses. Students should also try to attend and achieve a high GPA while focusing at the same time on practical issues and skills that the business needs. In addition, chambers of industry and commerce could play a major role in enhancing university-business collaboration by developing networks between graduates and labour market as well as by linking between graduate employability skills and labour market demand. Moreover, Ministry of higher education could develop policies to encourage and integrate employability skills in the study curriculums in different fields.

\section{Limitations}

Two limitations apply to this research. Firstly, the two samples may not big enough. Hence, expanding the samples may give better and unbiased results. Secondly, this study did not consider many other factors that would play a role in determining the graduates' performance such as quality standards, teaching staff. Further research could include those variables in order to get more comprehensive and accurate results.

\section{References}

Alias, M., Sidhu, G. K., \& Fook, C. Y. (2013). Unemployed graduates' perceptions on their general communication skills at job interviews. Procedia - Social and Behavioral Sciences, 90, 324-333. https://doi.org/10.1016/j.sbspro.2013.07.098

Bratti, M., McKnight, A., Naylor, R., \& Smith, J. (2004). Higher education outcomes, graduate employment and university performance indicators. Journal of the Royal Statistical Society. Series A: Statistics in Society, 167(3), 475-496. https://doi.org/10.1111/j.1467-985X.2004.0apm1.x

Clayson, D. E., \& Haley, D. A. (2015). Marketing models in education: students as customers, products, or partners'. Marketing Education Review, 15(1), 1-10. https://doi.org/10.1080/10528008.2005.11488884

Eagle, L., \& Brennan, R. (2007). Are students customers? TQM and marketing perspectives. Quality Assurance in Education, 15(1), 44-60. https://doi.org/10.1108/09684880710723025

Guilbault, M. (2016). Students as customers in higher education: reframing the debate. Journal of Marketing for Higher Education, 26(2), 132-142. https://doi.org/10.1080/08841241.2016.1245234

Hongjie, L., \& Zhenjia, S. (2019). Study on the definition of college students' employability. ITM Web of Conferences, 25, 1-2. https://doi.org/10.1051/itmconf/20192504001

Jackson, D. (2014). Factors influencing job attainment in recent Bachelor graduates: evidence from Australia. Higher Education, 68(1), 135-153. https://doi.org/10.1007/s10734-013-9696-7

Junek, O., Lockstone, L., \& Mair, J. (2009). Two perspectives on event management employment: student and employer insights into the skills required to get the job done! Journal of Hospitality and Tourism Management, 16(1), 120-129. https://doi.org/10.1375/jhtm.16.1.120

Lauder, H., Brown, P., Dillabough, J., \& Halsey, A. (2006). Introduction: the prospects for education: individualization, globalization, and social change. In H. Lauder, P. Brown, J. A. Dillabough, \& A. H. Halsey (Eds.), Education, globalization, and social change (pp. 1-70). Oxford: Oxford University Press.

Pheko, M. M., \& Molefhe, K. (2017). Addressing employability challenges: a framework for improving the employability of graduates in Botswana. International Journal of Adolescence and Youth, 22(4), 455-469. https://doi.org/10.1080/02673843.2016.1234401 
Salhani, A.; Khnouf, V.; Al-Zrair, R.; Dalati, S. 2019. The internal university factors in determining the graduates' performance in the labour market: evidence from Syrian universities

Pool, L. D., \& Sewell, P. (2007). The key to employability: developing a practical model of graduate employability. Education and Training, 49(4), 277-289. https://doi.org/10.1108/00400910710754435

Salhani, A., \& Khnouf, V. (2017). University-business research collaboration in Syria: an empirical assessment and suggested conceptual model. In J. Marx Gómez, M. Aboujaoude, K. Feghali, \& T. Mahmoud (Eds.), Modernizing academic teaching and research in business and economics. Cham: Springer. https://doi.org/10.1007/978-3-319-54419-9_11

Sumanasiri, E. G. T., Yajid, M. S. A., \& Khatibi, A. (2015). Review of literature on graduate employability. Journal of Studies in Education, 5(3), 75-88. https://doi.org/10.5296/jse.v5i3.7983

Taran, T., \& Liv, A. S. (2015). Study and labour market effects of graduate students interaction with work organisations during education: a cohort study. Education and Training, 57(7), 702-722. https://doi.org/10.1108/ET-10-2014-0126

Tenorio-Rodríguez, M., Padilla-Carmona, M., \& González-Monteagudo, J. (2018). Learning careers of non-traditional students on employability skills. In Continuity and discontinuity in learning careers: potentials for a learning space in a changing world (pp. 133-142). Brill | Sense.

Ward, L., McAdie, T., Bravington, A., \& King, N. (2012). The process of designing and analyzing a qualitative study into multiple work integrated learning experiences. University of Huddersfield, UK. 